\title{
Analysis of environmental problems of crop production and ways to solve them
}

\author{
Yuri Shirokov ${ }^{1, *}$ and Valery Tikhnenko ${ }^{1}$ \\ ${ }^{1}$ Russian state agrarian University-Moscow agricultural Academy K. A. Timiryazeva, 49, \\ Timiryazevskaya str., 127550, Moscow, Russia
}

\begin{abstract}
The article deals with engineering and technological problems of improving the environmental safety of crop production as a complex biotechnical system, for the environment, consumers of crop production and machine operators who ensure production in the field. It is noted that the impact of agriculture on the environment and humans is not only promoting global warming, participation in environmental pollution by pesticides and undigested remnants of mineral and organic fertilizers, the pollution of the production of field crops with residual amounts of pesticides and food is not absorbed nitrogen, toxic threat environment in the area of the machine, but unsustainable use of non-renewable resources, the availability of which depend on agricultural technologies. The main directions of minimizing environmental pollution and reducing dependence on non-renewable resources as a result of agricultural activities are shown.
\end{abstract}

\section{Introduction}

The world's concern about environmental problems is most related to the reduction of emissions of ozone-depleting substances and greenhouse gases, which, according to many scientists, affect climate change on Earth. The work in this direction is supported by the political decision of our country: September 23, 2019. Russia has ratified the Paris Climate Agreement. It assumes that the state's efforts will focus primarily on the fight to reduce greenhouse gas emissions into the atmosphere. It should be noted that agriculture also makes a significant contribution to such emissions.

The global community's efforts to prevent climate change are primarily focused on reducing carbon dioxide (CO2) emissions. However, methane $(\mathrm{CH} 4)$, nitrous oxide $(\mathrm{N} 2 \mathrm{O})$ and other greenhouse gases (which do not contain $\mathrm{CO} 2$ ) released during crop and livestock production also contribute to global warming.

Agriculture is a complex biotechnical system that includes a set of people, living biological objects and technical devices, the interaction of which allows you to get the necessary amount of agricultural products of the desired quality. However, the processes of interaction between humans, biological objects and technical devices are not limited within the system and are accompanied by a noticeable impact on the environment. In our opinion, agroengineering science can make a significant contribution to improving the environmental safety of agriculture.

* Corresponding author: shirokov001@mail.ru 
According to FAO estimates, in the agricultural sector, greenhouse gas emissions alone have almost doubled in the past 50 years and, if no measures are taken to reduce them, could increase by another $30 \%$ by 2050 . This is the main component of the global environmental problem of agriculture, since the concern in the world is most associated with reducing emissions of ozone-depleting substances and greenhouse gases, which, according to many scientists, affect climate change on Earth.

Greenhouse gas emissions in the agricultural sector of Russia amount to more than 142.4 million tons of CO2 equivalent. The most significant sources are direct emissions of nitrous oxide from agricultural soils, methane emissions from internal fermentation and disposal of manure in domestic animals, amounting to $38.3,28.0$ and $17.0 \%$, respectively [1-4]. In addition to the mentioned greenhouse gases, agricultural enterprises annually emit more than 25 thousand tons of pollutants into the atmosphere.

In the area of livestock complexes and poultry farms, the atmospheric air is polluted with microorganisms, dust, ammonia and other animal waste products, which often have unpleasant odors (more than 45 different substances). The most significant sources are direct emissions of nitrous oxide from agricultural soils, methane emissions from internal fermentation and disposal of manure in domestic animals, amounting to 38.3, 28.0 and $17.0 \%$, respectively [2-3]. In addition to the noted greenhouse gases, agricultural enterprises annually emit more than 25 thousand tons of greenhouse gases into the atmosphere. tons of pollutants. Livestock production and the products of this industry cause annual emissions of more than 32 billion tons of greenhouse gases, which is more than half (about $51 \%$ ) of all emissions on a global scale (Robert Goodland, Jeff Anhang, Livestock and Climate Change, / World Watch).

Chemical and biological pollution of atmospheric air is largely promoted by organizational reasons (low production culture) and insufficiently developed technologies of livestock complexes, poultry farms, greenhouses and mushroom-growing factories. In the area of livestock complexes and poultry farms, the atmospheric air is polluted with microorganisms, dust, ammonia and other animal waste products, which often have unpleasant odors (more than 45 different substances).

For example, emissions from the use of synthetic fertilizers accounted for $13 \%$ of all agricultural emissions (725 million tons of carbon dioxide equivalent) in 2011. Synthetic fertilizers are the fastest-growing source of agricultural emissions, having increased by $37 \%$ since 2001 [5]. In crop production, emissions from the combustion of mineral fuels in internal combustion engines during the operation of mobile field machines: at consumption in 2018. 3322tys. emissions in Russia's agriculture are more than 105,000 tons of CO2, 150,000 tons of nitrogen oxides, and 1,32,000 tons of sulfur oxides. Emissions from fuel combustion in thermal and drying processes of primary processing of agricultural products - more than 1 million tons, respectively, emissions of $\mathrm{CO} 2-32,000$ tons, nitrogen oxides60,000 tons, sulfur oxides-more than 44,000 tons.

Environmental problems are not just environmental pollution and climate warming. Forecasts of the depletion of proven reserves of raw materials for phosphorus and potash fertilizers should be a serious warning for their irrational use. Improving the ecological efficiency of biotechnical systems of agriculture is possible through the rational application of minimizing tillage in the conditions of soil and climatic zones and the established crop rotation in the Russian Federation. Minimization of the use of fertilizers and pesticides(by $10-30 \%$ ) due to growth stimulators of biological origin. Minimization of emissions of polluting gases, bacteria and heat from large closed production facilities in agricultural areas : livestock complexes, poultry farms and closed-ground enterprises. Minimizing the use of mineral fuels in heating and drying processes, sh

Emissions from the combustion of mineral fuels in internal combustion engines in a field of machines: when consumed in 2018. 3322тыс. tons dizelnogo fuel emissions in 
agriculture of Russia amount of CO2 - more than 105000 tons of nitrogen oxides - 150000 tonnes of sulphur oxides -132000 tons.

Emissions from fuel combustion in thermal and drying processes of primary processing of agricultural products - more than 1 million tons, respectively, emissions of CO2-32,000 tons, nitrogen oxides-60,000 tons, sulfur oxides-more than 44,000 tons.

Reducing the level of these types of pollution is possible through the use of precision farming systems. At the same time, there is a prospect of not only reducing emissions and discharges that pollute the atmosphere and water resources, but also a partial solution to another environmental problem: the rational use of non-renewable subsurface resources, in particular, a noticeable saving of phosphorus and potassium is possible.

Environmental problems are not only environmental pollution and climate warming [610]. Forecasts of the depletion of proven reserves of raw materials for phosphorus and potash fertilizers should be a serious warning for their irrational use. The emerging shortage of phosphorus, potassium and other non-renewable resources necessary for the formation of the crop, can put intensive agriculture in a dead end in the coming decades. Even more prudent use of mineral fertilizers in precision farming will only briefly delay the moment of their drying up. Moreover, in order to obtain immediate benefits for the owners of production from export outside the country (Russian agriculture consumes no more than $14 \%$ of the mineral fertilizers produced in the country - about 3.3 million tons per 82 million tons).ha of arable land - the level of the early 70 s of the last century. At the end of the 80 s, the RSFSR consumed up to 9.9 million tons per 132 million hectares of arable land - that is, twice the current level).

In this regard, it is necessary to intensify efforts to adapt agricultural technologies to the Russian conditions, allowing for the return of minerals absorbed by the non-commodity part of the crop to the soil.

At the same time, the situation with nitrogen and phosphorus is quite different. Nitrogen — although in a molecular form that is inaccessible to plants and animals-is present in huge quantities in the air. The bacteria that live in the nodules on the roots of legumes can bind it and turn it into a form suitable for use by plants. According to Brazilian agricultural research, more than $76 \%$ of the total nitrogen content in the harvested crop of cereals and cereals is due to biological nitrogen fixation, and only less than $20 \%$ is accounted for by chemical fertilizers. By adopting the sideration method, Brazil is moving closer to its goal of reducing greenhouse gas emissions by $43 \%$ by 2030 compared to 2005 levels.

Environmental problems of agriculture as a complex biotechnical system can be divided into five main components: these are, as noted above, the impact on the climate of the planet; the impact on the state of the hydrosphere and lithosphere; the impact on the depletion of non-renewable resources; the impact on the health of living and future generations of people; impact on the health of machine operators working in the field If the first three components are global, concern some distant future of the planet and its population, then the fourth and fifth affect the interests of every consumer of agricultural products and every agricultural worker today, directly affecting their health and quality of life.

The efforts of agricultural and agroengineering science, the actions of many international agreements, federal laws, environmental and sanitary norms and regulations are aimed at solving the environmental problems of agriculture, but since there is no noticeable effect, these measures are not enough

The purpose of the analytical work is to assess the main environmental problems of agriculture and ways to solve them using the best available technologies.

The research methodology is based on the study and generalization of the results of studies of the types and levels of crop production impact on the environment and the possibilities of reducing this impact by agrotechnological and agroengineering solutions. 
United Nations (2015) Resolution adopted by the General Assembly on 25 September 2015, Transforming our world: the 2030 Agenda for Sustainable Development $(\mathrm{A} / \mathrm{RES} / 70 / 1)$

\section{Results and discussion}

\subsection{Influence on the planet's climate}

Greenhouse gas emissions in the agricultural sector of Russia amount to more than 142.4 million tons of $\mathrm{CO} 2$ equivalent. Synthetic fertilizers are the fastest growing source of agricultural emissions. The volume of emissions generated by the use of synthetic fertilizers is $13 \%$ of all emissions in agriculture (725 million tons of carbon dioxide equivalent) [1,68].

Mechanization of crop production also makes a significant contribution to environmental pollution. When Russian agriculture consumed 3,322 thousand tons of diesel fuel in 2018, emissions into the atmosphere amounted to: CO2-more than 105,000 tons, nitrogen oxides-150,000 tons, sulfur oxides-132,000 tons [2].

In the agricultural production of Russia, significant air pollution also occurs due to the burning of large amounts of mineral fuels in boiler houses and drying plants. Due to the climatic features of most regions, up to $40 \%$ of the energy resources consumed in agriculture are spent on heating rooms and drying agricultural products. In most thermal processes, fuel oil, furnace fuel, and coal are used as an energy source, which leads to air pollution by the products of their combustion and makes an additional contribution to reducing the reserves of non-renewable energy sources.

Emissions from fuel combustion in thermal and drying processes of primary processing of agricultural products - more than 1 million tons, respectively, emissions of CO2-32,000 tons, nitrogen oxides-60,000 tons, sulfur oxides-more than 44,000 tons.

The second component of the environmental problem of agriculture is related to the fact that, along with greenhouse gas emissions, crop production has a serious impact on the state of the hydrosphere and lithosphere by polluting the environment with pesticides, the part of mineral fertilizers not assimilated by plants, and heavy metals.

People who are directly exposed to pesticides are most at risk. This category includes tractor drivers who treat fields with pesticides, and people who are in the surrounding area during and immediately after the spraying of pesticides.

The long-term use of pesticides in huge agricultural and forest areas, often with the use of aviation, has led to large-scale environmental pollution. The molecules of toxic chemicals (especially persistent compounds) are involved in the natural processes of migration and circulation of substances and are carried along with atmospheric flows over long distances. But most importantly, they are included in the ecological food chains: from the soil they enter water and plants, then into the organisms of animals and birds, and ultimately, with food and water, into the human body. And at every stage of migration, they cause harm and damage.

Studies have shown that if by the beginning of the sixties of the last century (the beginning of intensive chemicalization of agriculture) per capita accounted for $5 \mathrm{~kg}$ of chemical products used in agriculture, children with genetic abnormalities were born $0.74 \%$ of the total number, then by the end of the eighties, the mass of chemicals entering the country's farmland increased to $25 \mathrm{~kg}$ per capita. The number of children born with genetic disorders increased to $16.5 \%$. Biologists have found that a population that is $30 \%$ "corrupted" genetically is doomed to degeneration. 
A significant contribution to environmental pollution is made by the part of mineral fertilizers that is not absorbed by plants. The higher the yield of fertilizers, the greater their share is not absorbed. Moreover, mineral fertilizers simultaneously carry a number of heavy metals to the fields. Most of all, heavy metals accompany phosphorus fertilizers. Among the elements contained in a simple superphosphate, cadmium, chromium, cobalt, copper, lead, nickel, vanadium, and zinc may be present. Heavy metals also contain some pesticides - such as mercury, copper, zinc, and iron.[4,5].

Another type of negative impact of mineral fertilizers (in this case, nitrogen fertilizers) on the natural environment is the excessive accumulation of nitrates in the soil and agricultural crops, their migration to ground and surface waters. Under certain conditions, nitrates can turn into nitrosamines - carcinogenic substances that provoke the formation of malignant tumors.

The third component of the ecological problem of crop production is not the rational use of irreplaceable resources of the planet, including those that ensure the implementation of agrotechnical operations (fuels and lubricants) and support high crop yields (macro and micro fertilizers). Forecasts of the depletion of proven hydrocarbon reserves (according to expert estimates, Russia has about 14-18 billion tons).tons of oil-enough for another 25-30 years, the world's proven reserves-for about 53 years), reserves of raw materials for phosphorus and potash fertilizers and other non-renewable resources of the Earth's interior should be a serious warning for their irrational use, including in agriculture.

The emerging shortage of phosphorus, potassium and other non-renewable resources necessary for the formation of the crop, can put intensive agriculture in a dead end in the coming decades. At the same time, the situation with nitrogen and phosphorus is quite different. Nitrogen - although in a molecular form that is inaccessible to plants and animals-is present in huge quantities in the air. In many countries, the amount of nitrogen introduced into the soil with artificially synthesized fertilizers exceeds the amount that is bound on land during natural nitrogen fixation by bacteria. Therefore, the process of industrial fixation (binding) of atmospheric nitrogen and its transformation into an ammonium form (the Haber-Bosch process) allows the issue of nitrogen nutrition of plants not to be dramatized as long as it can be provided energetically: about $4,700 \mathrm{kWh}$ of thermal energy, $415 \mathrm{kWh}$ of electrical energy and 6,300 $\mathrm{kWh}$ of energy stored in the methane used in the synthesis process is consumed for the production of 1 ton of ammonia. But the limitation may be hydrogen, which is involved in the reaction, because it is obtained from non-renewable resources with a finite supply: oil, coal, natural gas.

With phosphorus, the situation is fundamentally different. Its reserves, according to pessimistic forecasts, will last for 40-50 years, according to optimistic ones-for 150 years. Moreover, in order to obtain immediate benefits, more than $85 \%$ of the phosphorus fertilizers produced are exported outside the country every year (Russian agriculture consumes no more than $15 \%$ of the mineral fertilizers produced in the country: about 3.3 million tons per 82 million tons).ha of arable land - the level of the early 70 s of the last century. At the end of the 80s, the RSFSR consumed up to 9.9 million tons per 132 million hectares of arable land - that is, twice the current level). It is not yet possible to produce phosphorus in production conditions. At the same time, phosphorus plays an extremely important role in the life of plants. It is found in the cellular protoplasm, is a part of chromosomes, nucleic acids, phosphoproteins, some vitamins, enzymes, esters, phytin, and other organic substances, and is actively involved in the formation of protein substances. In the processes of respiration and fermentation, one of the central functions is performed by phosphoric acid, which is a buffer in the regulation of carbohydrate metabolism.

To no lesser extent, plants need potassium. The lack of potassium causes many metabolic disorders in plants: the activity of a number of enzymes is weakened, carbohydrate and protein metabolism is disrupted, and the cost of carbohydrates for 
respiration increases. As a result, the productivity of plants decreases, the quality of products decreases. In cereals, a puny grain is formed, the germination and viability of seeds are reduced. The content of starch in potato tubers, sucrose in sugar beet roots, and pectin substances in fruits and berries decreases. With a deficiency of potassium, the susceptibility of plants to various diseases increases. But the total reserves of potassium in soils are many times (5-50) higher than nitrogen and phosphorus. Moreover, it is established that not only arable, but also sub-arable soil horizons take part in the supply of plants with potassium. This should be taken into account when choosing agricultural technologies and types of crops in the crop rotation.

The fourth part of the ecological problem of crop production is the impact on the health of living and future generations of people and is associated with the accumulation of residual amounts of pesticides, undigested forms of nitrogen in the form of nitrates and nitrites, which negatively affect the health of living and future generations of people [10-12. For the population, the main route of entry of pesticides into the body is enteral, i.e. through the gastrointestinal tract. Pesticides that are persistent in the environment enter the human body in $95 \%$ of cases with food, in $47 \%$ with water, only in $0.3 \%$ - with atmospheric air through the respiratory tract and very slightly-through the skin. In the world, 1 million acute poisonings with pesticides are registered annually, of which 20 thousand are registered. with fatal outcomes; thus, for every 500 cases of intoxication*, there is 1 fatal case [13].

During the last decade, due to the improvement of the range of pesticides used, their average toxicity decreased by 2.3-9 times [35], which, accordingly, reduced the number of acute poisoning. However, some highly toxic banned pesticides (for example, heptachlor, dieldrin, mirex, etc.) continue to be found in food, due to their large stocks in many farms of the country and in individuals, as well as the ability of these substances to selectively accumulate in various tissues (for example, organochlorine pesticides are able to selectively accumulate in adipose tissues). Pesticides, entering the human body in large doses, affect almost all organs, causing various severity of dystrophic changes in tissues, disrupting metabolism, inhibiting the functions of the central and peripheral nervous systems. [6-8]. Nitrates are nitric acid salts that accumulate in food and water when nitrogen fertilizers are too high in the soil. Researchers in the United States, Germany, Czechoslovakia, and Russia have found that nitrates and nitrites cause methemoglobinemia, stomach cancer, and have a negative effect on the nervous and cardiovascular systems, as well as on the development of embryos. (Methemoglobinemia is oxygen starvation (hypoxia) caused by the transition of blood hemoglobin to methemoglobin, which is not able to carry oxygen). Methemoglobin is formed when nitrites enter the bloodstream. When the content of methemoglobin in the blood is about $15 \%$, lethargy, drowsiness appears, with a content of more than $50 \%$, death occurs, similar to death from suffocation. The disease is characterized by shortness of breath, tachycardia, cyanosis in severe cases - loss of consciousness, convulsions, death. Nitrites, interacting with amines, form compounds that have carcinogenic properties.

The fifth component of the ecological problem of crop production is the combined effect of pesticides used in crop production, dust introduced into the soil by spreading mineral fertilizers, emissions of fuel combustion products in the engines of mobile agricultural machines on the health of machine operators [12-14]. At first glance, the problem is local, but it has a great social significance. Regular contact of machine operators (during the growing season, the tractor driver has to apply pesticides 8-12 times, each time working with them for several days) with a large amount of pesticide, both in the process of preparing tank mixes, in the process of spraying, in the process of washing machines after processing, can cause acute poisoning or long-term negative health consequences, including cancer and reproductive disorders. With a complex exposure to a mixture of pollutants, even if the content of each of them is below the MPC level, as a rule, an increase in toxic 
effects on the human body is detected, and the probability of poisoning increases. The occupational morbidity of rural workers has led to the fact that for 10-12 years before the retirement age, $70 \%$ of trained and highly qualified machine operators leave the work of tractor drivers. According to the All-Russian Research Institute of Labor Protection (VNIIOT) About $75 \%$ of tractor drivers do not live up to the retirement age of the Ministry of Agriculture of Russia.

\section{Offers}

To really reduce the negative impact of crop production on the environment and humans, it is necessary to work more closely with agricultural and agroengineering science and practice to improve and accelerate the introduction of the best available technologies in agricultural practice in the following areas:

1. Activation of the introduction of available elements of precision farming systems witthe transition to their mass system application. The least time and resources are needed for the mass implementation of precision farming systems, which, along with increasing the profitability of production, can reduce the level of soil and environmental pollution, the involvement of residual amounts of pesticides and undigested fertilizers (primarily nitrogen, an irrational excess of which contributes to the formation of nitrates and nitrites in products).

For the introduction of precision farming technologies, there is a necessary technical, technological and information base. What is important is the desire (economic incentives) of the landowners and the competence of the staff.

Equipment and information technologies allow you to get the most important information about the actual productivity of sown areas, the so-called yield maps. Using sensors installed on the harvesting equipment, as well as on-board computers and GPS receivers, after harvesting the harvested crops, we can obtain spatially oriented yield maps. The resulting maps are included in the geo-information base of the farm and serve as a starting point for planning an agrochemical survey. This information significantly reduces the cost of field survey, as it allows you to purposefully identify the most important places for the survey.

To implement this method, serious preparatory work is required for the survey of agricultural fields, when each soil sample taken is linked to a single positioning system, which in the future allows you to more accurately evaluate the results of successive rounds of the survey. Along with the precise recording and storage in the computer of the coordinates of each sample taken in the surveyed area, the new technology provides automatic creation of an electronic map-a survey scheme with the specified dimensions of the elementary area. This survey map defines the structure of the future geoinformation database [15].

On this basis, agricultural technologists can accurately calculate the amount of seeds, fertilizers and other resources for each section of the field with high accuracy, and field machines can provide the same exact execution.

Moreover, modern equipment from leading manufacturers provides the introduction of not only the specific volume and type of nutrients or plant protection products, but also accurate delivery of them to the root system (seeders of the type ED or EDX (Amazone), Pronto DS( Horch), mechanical grain seeder "Nika-4" SPM, Seeder SUPN-8 fan, FALCON PRO potato planter SKR 01.000, (Grimme), etc.).

For example, the Amazone ED seeder is compatible with ISOBUS, which allows comfortable operation with professional electronic equipment via AMATRON 3, CCI 100, AMAPAD and other ISOBUS terminals. In the Basic equipment, the ED Special seeder is controlled via an AMASCAN computer (the video terminal is shown in Fig.). 
In satellite driving, gaps and overlaps between the treated areas are not allowed a priori, which eliminates resource overruns or doubling the dose. This makes an additional contribution to environmental safety. With automatic section-by-section activation of the GPS-Switch, AMAZONE offers a system based on the GPS satellite navigation system that allows fully automatic activation of sections for all AMAZONE control terminals

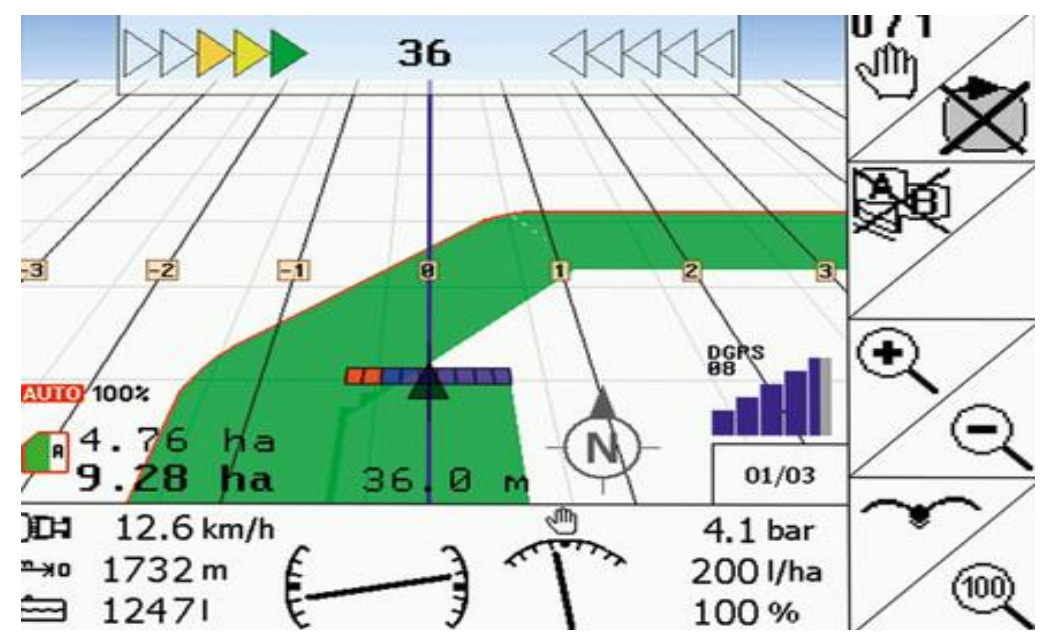

Fig. 1. Video terminal of the AMASCAN computer for controlling the ED Special seeder (Source: https://www.promintel-agro.ru/images/Amazone/ED/ED) and ISOBUS-dispensers, - sprayers and seeders.

At the same time, there is a prospect of not only reducing emissions and discharges that pollute the atmosphere and water resources, but also a partial solution to another environmental problem: the rational use of non-renewable subsurface resources, in particular, it is possible to significantly save oil products, phosphorus and potassium.

It is necessary to pay attention to the long-term experience of agriculture in Brazil. Here, less than $30 \%$ of the nitrogen nutrition of plants is accounted for by chemical fertilizers, more than $76 \%$ of the total nitrogen content in the harvested crop of cereals and cereals is due to biological nitrogen fixation. It has long been known that bacteria living in nodules on the roots of legumes can transform atmospheric nitrogen into a form suitable for use by plants more efficiently, both from an ecological, economic and energy point of view. Brazil is moving closer to its goal of reducing greenhouse gas emissions from agricultural activities by $43 \%$ by 2030 , compared to 2005 levels, as it develops green manure techniques.

Since pesticides are by definition toxic and intentionally released into the environment, the use of pesticides should be subject to strict regulation and control. In this regard, a great contribution to environmental safety is made by the use of low-volume sprayers such as OP 2000 , etc. A distinctive feature of the operation of low-volume sprayers in comparison with traditional sprayers is the greater dispersion of the spray and higher quality of processing, in particular, better penetration of the working fluid into the crown of plants, greater uniformity and density of the leaf coating, and the absence of liquid runoff from the plant surface to the soil.

All these factors make it possible, with high technical efficiency, to significantly reduce the consumption of liquids and pesticides, and to reduce the degree of soil contamination. However, agroengineering science needs to continue its research work on further improving low-volume spraying systems in the direction of automating the processes of preparing tank mixtures (eliminating the tractor driver from this operation), developing systems for night driving of aggregates without the presence of a person, creating systems for automatic 
flying sprayers based on quadracopters (drones) with clear positioning to avoid overlapping processing zones.

2. Minimization of tillage in the conditions of soil-climatic zones and the established crop rotation in the Russian Federation. In connection with environmental problems, it is necessary to intensify efforts to adapt agricultural technologies to Russian conditions, which allow for the return of mineral substances absorbed by the non-marketable part of the crop to the soil.

The ecological and economic efficiency of minimum and zero tillage technologies is estimated by many farmers in different regions of the world, as they have been used for more than half a century on tens of millions of hectares. In Russia, due to the specifics of crop rotations, traditions and soil and climatic conditions, the process of introducing minimum and zero tillage technologies is very slow.

It is important that the use of" No-Till " ensures the return of crop residues to the soil. In this case, most of the phosphorus and potassium are returned to the environment when leaching (potassium) and decomposition of organic residues by microorganisms. The use of straw increases the content of mobile forms of phosphorus and potassium. This increases the mineralization of hard-to-reach phosphates by activating phosphorous bacteria. The carbohydrates that make up the straw are used in the metabolism of bacteria that can fix atmospheric nitrogen. The ratio of microbiological processes of nitrogen mobilization and immobilization is noticeably shifted towards the predominance of the latter, as a result of which most of the introduced nitrogen is fixed in the soil in organic form.

The amount of straw and other by-products depends on the cultivated crop, the variety, and the fertilizers used. In order to calculate the amount of nutrients that straw can return, you need to make very simple calculations: with an average national yield of $22.4 \mathrm{c}$ of grain per hectare (2019), about $47.8 \mathrm{c}$ of organic mass remains in the field (31.4 c of straw and floor, 16.2-the underground part of the biomass). As a result, after the decomposition of plant residues, the soil of each hectare will receive: $42.5 \mathrm{~kg}$ of nitrogen, $21.25 \mathrm{~kg}$ of phosphoric anhydride, $68 \mathrm{~kg}$ of potassium oxide. But on the whole area of grain crops (28 million acres) - 1,190 million tons of nitrogen, 0,595 million tons of phosphorus, 1,904 million tonnes, i.e. a total of 3,689 million tons of nutrients (comparable to the amount made in 2019 of mineral fertilizers for all the sh culture in the square 79 million ha).

In addition, the ground return trace elements necessary for regulation of metabolism in the organisms of plants and yield formation:. boron - 21-25 grams per ton of straw, copper-12-15 grams, manganese-13-15 grams, molybdenum-1.7 -2 grams, zinc-170-200 grams, Cobalt-0.4-0.5 grams [16].

Moreover, in traditional plowing, straw scattered over the field is laid at the bottom of the furrow during the turn of the formation, forming a buffer layer between the loose soil and the subsurface layer. Capillary moisture, rising up, condenses on the straw layer and remains under it, without being able to get into the habitat of plant roots. This effect is not noticeable at yields of up to $20 \mathrm{c}$ /ha (about 2 tons of straw per hectare), but becomes significant with an increase in yield.

With minimal technologies, straw and crop residues are mixed with the top layer of the soil (preferably no deeper than $200 \mathrm{~mm}$ ), eliminating the above - mentioned effect of isolating the soil from subsurface layers, while replenishing the soil with organic matter. It is known that to accelerate the destruction of organic substances of straw, it is advisable to treat it with urea before laying it in the soil and enrich the soil with microbiological preparations. It is necessary to develop technologies and form a system of machines on the example of typical (model) farms in various soil and climatic conditions in order to identify the limits of applicability and efficiency of technologies for the cultivation of basic agricultural crops with the use of minimal and zero tillage. To do this, it is necessary to form machine systems, develop technological methods for cultivating the main agricultural 
crops using minimal and zero tillage, and investigate the environmental and economic features and advantages of minimal and zero tillage in each soil and climate zone:

- reduction of $\mathrm{CO} 2$ emissions into the atmosphere by reducing fuel consumption (50-60 $1 /$ ha instead of 100-1201/ ha);

- reducing the pressure on the soil by reducing the number of MTA passes;.

- reduction of $\mathrm{CO} 2$ emissions into the atmosphere by eliminating the burning of crop residues;

- reducing the chemical load by reducing the use of herbicides;

- prevention of soil erosion, etc.

Indirect environmental effect: reduced consumption of petroleum products (approximately twice), reduced metal consumption of the vehicle fleet (by 30-40\%). Fuel consumption while minimizing tillage is reduced to $56-65 \mathrm{~kg} /$ ha compared to $90-120 \mathrm{~kg} /$ ha with a traditional farming system

. The maximum effect of preserving soil moisture and accumulating humus is provided by direct sowing on mulch: a layer of straw that is left on the surface of the soil, prevents its overheating and evaporation of subsurface moisture. This effect will be of increased importance with further warming of the climate.

3. Reducing the consumption of petroleum products. Minimizing tillage also has an additional environmental effect: reducing the consumption of petroleum products from 90$120 \mathrm{~kg}$ / ha under the traditional farming system to $56-65 \mathrm{~kg} / \mathrm{ha}$. (approximately twice), In addition, the metal consumption of the fleet of machines is reduced (by 30-40\%), which reduces energy consumption both for their production and the production of metals and other structural materials for the manufacture of agricultural machinery, which gives an indirect environmental effect

According to our calculations, this will reduce emissions in agriculture.: $\mathrm{CO} 2$ by 35,000 tons, nitrogen oxides by 50,000 tons, sulfur oxides by 44,000 tons (with consumption in 2018 of 3322 thousand tons of diesel fuel).

Therefore, agricultural science and practice face a problem: to effectively fit a system of machines for minimal and zero tillage into the technologies of cultivation of the main agricultural crops, taking into account the characteristics of the soil and the established crop rotation. It is necessary to develop technologies and form a system of machines on the example of typical (model) farms in various soil and climatic conditions in order to identify the limits of applicability and efficiency of technologies for the cultivation of basic agricultural crops with the use of minimal and zero tillage. To do this, it is necessary to form machine systems, develop technological methods for cultivating the main agricultural crops, traditional for Russia, using minimal and zero tillage, and to study the ecological and economic features and advantages of minimal and zero tillage in each soil and climate zone, taking into account the characteristics of the soil and the established crop rotation.

4. Minimization of the use of mineral fuels in thermal and drying processes of agricultural production.

In order to increase the environmental efficiency of agricultural production, it is necessary to intensify the use of the non-commodity part of the crop as fuel in the form of pallets, in some regions in the form of cellulose-oil suspensions based on a combination of vegetable residues of oilseeds and vegetable oils instead of fuel oil, furnace fuel and coal for small boilers and drying plants in agricultural production.

The effective use of such biofuels requires the creation of engineering solutions (technological equipment for production, for example, based on cavitation, and applications (new types of burners).

5. Minimization of the use of fertilizers and pesticides (by 10-30\%) due to growth stimulators of biological origin. 
The biologized system of agriculture can become a rational way of further development of agriculture in Russia. This will allow not only to provide the population of the country with environmentally friendly food, but also to take a leading place in the world market of such products. However, repeated or excessive introduction of such fertilizers into the soil is not only costly, but also harmful to the ecosystem. The method of rational application of fertilizers is the introduction of application systems using, for example, an N-sensor or differentiated application. Differentiated application of fertilizers (TLD) is one of the technologies of precision agriculture, which provides a change in fertilizer doses depending on the composition of the soil, the planned yield and the needs of each zone of the field .

The main thing that is necessary for accurate work is electronic field maps. To create them, we use: satellite

data processed using special programs;

mapping carried out using surveys from unmanned aerial vehicles (UAVs); yield

maps that are recorded by on-board computers of combines with the mapping function;

detour of fields with GPS equipment.

These maps are then plotted with analytical data obtained from the analysis of soil samples and the study of biomass using optical and sensor sensors. On the basis of these maps, technical tasks are formed and the necessary operations are performed.

Now two main process approaches are competing. They are conventionally called the offline and online approach. In the first case, the application rates for each section of the field are determined in advance, and the equipment works according to the already entered program with all calculations for each section of the field.

The online method allows you to calculate and correct the required amount of fertilizers directly during this operation in the field. This method resembles a step-by-step strategy, involving the use of sensors-spectrometers, which can be located on a moving tractor or on a UAV. The sensor emits light at two wavelengths and measures the reflection from the plant surface. The resulting difference in the red and infrared spectra is closely correlated with the density of vegetation and its nutrient saturation. Based on the data obtained, standardized indices of differences in vegetation cover are calculated - there are more than two dozen of them. Among them is the most well-known vegetation index NDVI. They are taken into account by a special program that determines the optimal norm for each section of the field according to a given algorithm. From the programs for controlling the drone, you can use DJI go/go4. When creating orthophotoplanes, DroneDeploy and Pix4D programs are used. You can use the Cropio system to store the flyby results. Experience shows that this approach reduces the consumption of fertilizers by $15-25 \%$ (Data from the Institute of Biophysics of the Russian Academy of Sciences),

Here we see several options. To do this, it is necessary to introduce elements into the technological process that can give an increase in productivity for the invested ruble more than mineral fertilizers. First, it is a rational introduction to the crop rotation of black vapors or siderates, primarily legumes, as a base for the soil factory for the production of assimilable nitrogen. Secondly, the maximum return to the soil of crop residues (straw, floorboards), which allows, in addition to using the returned nutrients, to increase the activity of soil microorganisms and the production of carbon dioxide in the soil and the ground layer of air. An increase in the concentration of carbon dioxide is a condition for activating photosynthesis and increasing productivity. But it should be borne in mind that with a high yield, when straw is formed more than $5 \mathrm{t} / \mathrm{ha}$, it is quite difficult to seal it in the soil.

Third, the use of plant growth stimulators of synthetic or natural origin. The use of modern growth-stimulating drugs, which, when used in a mixture with mordants, neutralize the negative effect of mordants on seeds and seedlings, but also activate germination and germination energy, the formation of the root system of plants, contribute to the formation 
of a more powerful tillering node in cereals and the growth of additional productive stems and, accordingly, ears. Increased root formation of plants leads to improved nutrition conditions and is accompanied by increased growth of the aboveground part of the plant. This means that it is necessary to adhere to the minimum limits of the seed seeding rates specified in the variety passport. I.e., the cost of seeds can be further reduced [12-14].

Synthetic fertilizers also contribute significantly to direct agricultural emissions.

$\mathrm{CO} 2$ emissions are considered to be zero, since the $\mathrm{CO} 2$ released into the air during combustion was previously absorbed from the atmosphere during plant growth (a closed cycle is formed that does not lead to an increase in the concentration of $\mathrm{CO} 2$ in the atmosphere.Gorenjeski).

In the process of transformation of plant residues, only a part of organic compounds is mineralized to $\mathrm{CO} 2$, and a part is used by microorganisms to build biomass, as a result of which the content of microbial carbon in the soil increases.

A certain contribution to this direction can be made by minimizing the use of mineral fertilizers and plant protection products by improving the metabolic processes in plants and increasing their resistance to diseases and pests when using stimulating drugs, especially of biological origin. In recent years, Russia and a number of other countries have been working to create a line of complex preparations, mainly of organomineral synthesis and biological origin (bio - nutrients), based on physical methods of activating the known and long - used in agricultural practice products of the metabolism of living organisms (animals-microorganisms-annelids). Such bio-nutrients, due to the activation of metabolic processes in plants, help to increase the immune status of plants and improve metabolic processes, thereby reducing the need for chemical pesticides and mineral fertilizers [6-8].

\section{Conclusion}

Science and industry already allow agriculture to use machine systems and technologies that can provide a sufficiently high level of environmental protection, the health of consumers of manufactured food products and the health of machine operators working in the field. However, the agricultural business is not concerned with environmental problems, because its goal is to get maximum profit with minimal investment. The risk of reducing the economic efficiency of the business and, moreover, its loss, with the introduction of not sufficiently proven and justified technologies, is not acceptable for agricultural production. Therefore, the problem of improving the environmental safety of agriculture cannot be solved without serious scientific support and appropriate state attention.

The influence of the state is possible primarily by economic levers, which allow not only tariffs for payments for emissions and discharges or fines for violations of environmental legislation, but primarily by incentives in the form of concessional loans, subsidies, leasing, tax minimization or provision of tax holidays, etc.to make it profitable for agricultural businesses to invest in environmentally efficient farming systems, technologies, projects.

Agricultural science, in turn, needs to justify the effective types and levels of economic incentives for the introduction of environmentally efficient systems of machines, technologies and projects; to deepen systematic research on the generalization, development and dissemination of experience in the introduction of environmentally effective agricultural technologies of precision agriculture, minimum and zero technologies; systems of machines available for their implementation, to justify the boundaries of their biologically and economically viable applicability in various crop rotations and soil-climatic zones of the country. 


\section{References}

1. F.N. Tubiello, Elsevier Encyclopedia of Food Systems (2019) DOI: 10.1016/B978-008-100596-5.21996-315

2. D. Carrington, Avoiding meat and dairy is 'single biggest way' to reduce your impact on Earth (The Guardian, 2018)

3. V. Morell, Meat-eaters may speed worldwide species extinction, study warns (Science, 2015)

4. B. Machovina, K.J. Feeley, W.J. Ripple, Science of the Total Environment 536, 419431 (2015) doi:10.1016/j.scitotenv.2015.07.022

5. M. Williams, J. Zalasiewicz, P.K. Haff et al., The Anthropocene Review 2(3), 196219 (2015) doi:10.1177/2053019615591020

6. R. Smithers, Vast animal-feed crops to satisfy our meat needs are destroying planet (The Guardian, 2017)

7. A. Woodyatt, Human activity threatens billions of years of evolutionary history, researchers warn (CNN, 2020)

8. M. McGrath, Humans 'threaten Im species with extinction' (BBC, 2019)

9. J. Watts, Human society under urgent threat from loss of Earth's natural life (The Guardian, 2019)

10. C.A. Damalas, I.G. Eleftherohorinos, International Journal of Environmental Research and Public Health 8(12), 140219 (2011) doi:10.3390/ijerph8051402

11. C. Lamberth, S. Jeanmart, T. Luksch, A. Plant, Science 341(6147), 7426 (2013)doi:10.1126/science. 1237227

12. S. Tosi, C. Costa, U. Vesco, G. Quaglia, G. Guido, The Science of the Total Environment 615, 208-218 (2018) doi:10.1016/j.scitotenv.2017.09.226

13. Environmental impacts of pesticides, https://www.slu.se/en/Collaborative-Centres-andProjects/centre-for-chemical-pesticides-ckb1/information-about-pesticides-in-theenvironment-/exposure-and-environmental-impact/

14. H.L. Tuomisto, I.D. Hodge, P. Riordan, D.W. Macdonald, Journal of Environmental Management 112, 30320 (2012) doi:10.1016/j.jenvman.2012.08.018 